\title{
Rumus Arah Kiblat Saadoeddin Djambek Perspektif Spherical Trigonometry
}

\author{
Fatmawati $^{1}$, Muhammad Shuhufi ${ }^{2}$, Rahma Amir ${ }^{3}$, Saiyed Amar Ahmad ${ }^{4}$ \\ UIN Alauddin Makassar \\ 1Email: fatmawati@uin-alauddin.ac.id
}

\begin{abstract}
Saadoeddin Djambek is a figure who was introducing astronomical formulas which were adapted from astronomical formulas. The research is about the comparison of Saadoeddin Djambek's Qibla direction formula in terms of spherical trigonometry theory in relation to the existence of an old theory and a new theory. This study measures the accuracy of the formula. This is because the formula is explained simply with derived formulas. Thus the formula options will be available that can be used in the measurement of Qibla direction so that the measurement of Qibla direction will be easier and simpler.
\end{abstract}

Keywords : Qibla Direction, Saadoeddin Djambek.

\begin{abstract}
Abstrak
Saadoeddin Djambek adalah tokoh yang sangat berperan dalam memperkenalkan rumus-rumus ilmu falak yang didaptasi dari rumus astronomi. Hal yang menarik bagi peneliti adalah tentang komparasi rumus arah kiblat Saadoeddin Djambek ditinjau dari teori spherical trigonometry dalam hubungannya tentang eksistensi suatu teori lama dan teori baru dalam satu bidang kajian ilmu Penelitian ini mengukur tingkat akurasi rumus. Hal ini karena rumus dipaparkan secara sederhana dengan rumus turunan berasal dari sumber yang sama maka hasil perhitungannya juga akan sama. Dengan demikian akan tersedia opsi/pilihan rumus yang dapat digunakan dalam pengukuran arah kiblat sehingga pengukuran arah kiblat akan lebih mudah dan sederhana.
\end{abstract}

\section{Artikel Info}

Received:

26 Agustus 2020

Revised:

19 September 2020

Accepted:

09 November 2020

Published:

02 Desember 2020

Kata Kunci : Arah Kiblat, Saadoeddin Djambek. 


\section{AL-MARSHAD: JURNAL ASTRONOMI ISLAM DAN ILMU-ILMU BERKAITAN \\ ISSN 2442-5729 (print) || ISSN 2598-2559 (online) \\ http://jurnal.umsu.ac.id/index.php/almarshad \\ DOI: 10.30596/jam.v\%vi\%i.5092 || Vol. 6, No. 2 Desember 2020}

\section{A. Pendahuluan}

Seiring perkembangan zaman, perhatian masyarakat terhadap penentuan arah kiblat semakin mengalami kemajuan dan perkembangan pesat. Masyarakat sudah mulai menerima kemajuan ilmu pengetahuan dengan memilih metode penentuan arah kiblat yang lebih akurat. Hal ini ditandai dengan semakin ditinggalkannya cara-cara lama penentuan arah kiblat seperti melihat arah terbenamnya matahari atau dengan cukup menentukan sesuai arah barat. Selain itu, kemajuan terhadap penentuan arah kiblat juga ditandai dengan semakin berkembangnya metode penentuan arah kiblat.

Perkembangan metode penentuan arah kiblat kemudian dapat dilihat pada berbagai aspek. Mulai dari semakin banyaknya inovasi berupa alat-alat yang dapat digunakan untuk menentukan arah kiblat, semakin banyaknya software yang dibuat untuk memudahkan penentuan arah kiblat, sampai pada pengembangan rumus dasar perhitungan arah kiblat.

Berbagai rumus kemudian dibuat untuk keperluan praktis. Di antara rumusrumus yang sering digunakan adalah rumus trigonometri bola dan rumus-rumus Saadoeddin Djambek yang dikembangkan dari rumus trigonometri bola dan rumus napier. Rumus-rumus inilah yang dikembangkan lagi menjadi rumus-rumus spherical trigonometry. Menarik untuk peneliti kaji secara komparatif antara rumus-rumus arah kiblat Saadoeddin Djambek dan rumus spherical trigonometry. Hal ini untuk mengetahui pengoperasian rumus-rumus tersebut serta variabel-variabel yang ada di dalamnya secara detail guna menemukan teori yang lebih benar atau semakin memperkuat teori yang sudah ada.

\section{Biografi Tokoh}

Saadoeddin Djambek adalah seorang ahli falak yang lahir di Bukit Tinggi, 24 Maret 1911 M/23 Rabiul Awal 1329 H. Beliau putra dari Syekh Muhammad Djamil Djambek (1860- 1947 M/ 1277-1367 H). ${ }^{1}$

Saadoeddin Djambek menempuh pendidikan formal sebagai berikut :

1. HIS (Hollands Inlandsche School), tamat pada tahun 1924,

2. HIK (Hollands Inlandsche Kweekschool) di Bukit Tinggi, tamat pada tahun 1927 ,

3. HKS (Hogere Kweekschool) di Bandung, tamat pada tahun 1930.

Ketertarikan Saadoeddin Djambek dalam ilmu hisab dimulai ketika ia berguru pada Syekh Taher Jalaluddin al-Azhari di al-

\footnotetext{
${ }^{1}$ Susiknan Azhari, Pembaharuan Pemikiran Hisab di Indonesia, (Yogyakarta : Pustaka Pelajar, 2002), h. 49.
} 


\section{AL-MARSHAD: JURNAL ASTRONOMI ISLAM DAN ILMU-ILMU BERKAITAN \\ ISSN 2442-5729 (print) || ISSN 2598-2559 (online) \\ http://jurnal.umsu.ac.id/index.php/almarshad \\ DOI: 10.30596/jam.v\% vi\%i.5092 || Vol. 6, No. 2 Desember 2020}

Jami'ah Islamiyah Padang pada tahun 1929. ${ }^{2}$ Sejak tahun 1930-1934 Saadoeddin Djambek mengajar di Gouvernements Schakelschool Perbaungan, Palembang dan kemudian pindah ke Jakarta pada tahun 1935 sebagai guru Gouvernement HIS. Karir beliau tidak berhenti sampai disitu, Saadoeddin Djambek terus melanjutkan pendidikan ke Indische Hoofdakte di Bandung dan selesai tahun 1937 di tahun yang sama beliau juga memperoleh ijazah bahasa jerman dan bahasa Perancis. ${ }^{3}$

$$
\text { Saadoeddin Djambek }
$$

memperdalam pengetahuannya di bidang ilmu pasti dengan mengikuti kursus Legere Akte di Yogyakarta tahun 1941-1942 kemudian melanjutkan pendidikan di FIPIA (Fakultas Ilmu Pasti dan Ilmu Alam) di Bandung pada 1954-1955. Saadoeddin Djambek kemudian berusaha mengembangkan sistem baru dalam perhitungan hisab dengan mengembangkan teori Spherical Trigonometry. ${ }^{4}$

Setelah menyelesaikan pendidikan di Bandung, Saadoeddin Djambek kembali menjadi guru Gouvernment HIS di Simpang Tiga, Sumatera Timur. Karir

${ }^{2}$ Susiknan Azhari, Ensiklopedi Hisab Rukyat, (Yogyakarta : Pustaka Pelajar, 2008), h. 206.

${ }^{3}$ Susiknan Azhari, Pembaharuan Pemikiran Hisab di Indonesia, h. 185.

${ }^{4}$ Susiknan Azhari, Pembaharuan Pemikiran Hisab di Indonesia, h. 50. saadoeddin Djambek terus meningkat hingga ia kemudian menjadi staf ahli Menteri Pendidikan dan Kebudayaan di Jakarta. ${ }^{5}$ Saadoeddin Djambek juga aktif di Muhammadiyah dan menjadi ketua Pimpinan Pusat Muhammadiyah Majelis Pendidikan dan Pengajaran di Jakarta periode 1969-1973. ${ }^{6}$ Saadoeddin Djambek meninggal dunia pada hari Selasa, 22 November 1977 di Jakarta. ${ }^{7}$

\section{B. Metode Penelitian}

Penelitian ini merupakan jenis penelitian library research (kepustakaan). Data-data yang dikumpulkan berasal dari sumber-sumber kepustakaan yang relevan dengan metode penentuan arah kiblat Saadoeddin Djambek dan metode penentuan arah kiblat spherical trigonometry. Sumbersumber primer berupa buku-buku yang terkait dengan metode penentuan arah kiblat Saadoeddin Djambek dan buku-buku terkait metode penentuan arah kiblat spherical trigonometry. Adapun sumber sekunder berupa buku-buku terkait biografi tokoh Saadoeddin Djambek, artikel-artikel terkait metode penentuan arah kiblat spherical trigonometry dan buku-buku serta tulisan-tulisan terkait dasar hukum penentuan arah kiblat.

\footnotetext{
${ }^{5}$ Susiknan Azhari, Pembaharuan Pemikiran Hisab di Indonesia, h. 186.

${ }^{6}$ Susiknan Azhari, Pembaharuan Pemikiran Hisab di Indonesia, h. 52.

${ }^{7}$ Nourouzzaman Shiddiqi, Fiqh Indonesia Penggagas dan Gagasannya, (Yogyakarta, Pustaka Pelajar, 1997), h. 61.
} 


\section{AL-MARSHAD: JURNAL ASTRONOMI ISLAM DAN ILMU-ILMU BERKAITAN \\ ISSN 2442-5729 (print) || ISSN 2598-2559 (online) \\ http://jurnal.umsu.ac.id/index.php/almarshad \\ DOI: 10.30596/jam.v\% vi\%i.5092 || Vol. 6, No. 2 Desember 2020}

Analisis yang digunakan adalah analisis komparatif yakni menggunakan logika perbandingan untuk membandingkan rumus penentuan arah kiblat Saadoeddin Djambek dan rumus spherical trigonometry. Hal ini dilakukan untuk mengetahui rumus mana yang lebih praktis dan akurat selain itu untuk mengetahui apakah teori yang baru menumbangkan teori lama atau memperkokoh keberadaan teori yang lama. ${ }^{8}$

Pengumpulan data dalam penelitian ini dilakukan dengan cara membaca kemudian melakukan pencatatan terhadap data-data yang dibutuhkan dalam penelitian untuk selanjutnya melalui proses seleksi dan penyederhanaan. Setelah itu data kemudian disajikan dalam bentuk pemaparan yang sistematis, sederhana namun jelas tertuju pada pokok permasalahan. Selain itu data disajikan pula dalam bentuk pemaparan hasil perhitungan dan tabel yang untuk selanjutnya disimpulkan secara singkat.

\section{Arah Kiblat}

Kiblat berasal dari kata - قبل - يقبل قبلة yang artinya menghadap ${ }^{9}$ merupakan

\footnotetext{
${ }^{8}$ Rizal Mustansyir, Filsafat Ilmu,

(Yogyakarta: UGM Press, 2001). h. 117.

${ }^{9}$ Ahmad Warson Munawir, Al-Munawir kamus Arab-Indonesia, (Surabaya: Pustaka
} Progressif, 1997), h.1087-1088. sinonim kata syatrah dan al-simt ${ }^{10}$ dan merupakan bentuk fi'lah dari kata almuqolabah sehingga berarti keadaan yang menghadap. ${ }^{11}$ Kiblat didefenisikan sebagai jarak terdekat bagi suatu tempat untuk menghadap ke Ka'bah di Mekkah. ${ }^{12}$ Selain itu Kiblat juga didefenisikan sebagai arah menghadap ketika melaksanakan sholat. ${ }^{13}$ Terkait kiblat, ensiklopedia Islam menyatakan "the word kiblat means the direction towards Macca" dinyatakan pula dalam ensiklopedia umum bahwa kiblat adalah Ka'bah atau Baitullah yakni bangunan berbentuk kubus yang terletak ditengah-tengah Masjidil Haram. ${ }^{14}$

Penentuan arah kiblat ini meliputi

${ }^{10}$ Departemen Agama RI., Pedoman Penentuan Arah Kiblat, (Jakarta: Dirjen Binbaga Islam, 1994), h. 10 .

${ }^{11}$ Majlis Tarjih Dan Tajdid Pimpinan Pusat Muhammadiyah, Pedoman Hisab Muhammadiyah, (Cet.II, Yogyakarta : Majlis Tarjih Dan Tajdid Pimpinan Pusat Muhammadiyah. 2009). h. 25.

${ }^{12}$ Slamet Hambali, Ilmu Falak I Tentang Penentuan Awal Waktu Shalat dan Penentuan Arah Kiblat Di Seluruh Dunia, (Semarang : PPS IAIN Walisongo Semarang, 2011), h. 84. lihat pula Kusdiono, Ilmu Ukur Segitiga Bola, (Bandung : Jurusan Teknik Geodesi, 2002), h. 38. dan Dendy Sugono, Kamus Besar Bahasa Indonesia Pusat Bahasa, (Jakarta : PT. Gramedia Pustaka Media, 2008), h. 695.

${ }^{13}$ Harun Nasution, Ensiklopedi Hukum Islam, (Jakarta: Djambatan, 1992), h. 563. lihat pula Nurmal Nur, Ilmu Falak: Teknologi Hisab Rukyat Untuk Menentukan Arah Kiblat, Awal Waktu Shalat dan Awal Bulan Qamariah, (Padang: IAIN Imam Bonjol Padang, 1997), h. 23.

${ }^{14}$ Ali Parman, Ilmu Falak, (Makassar: Alauddin University Press, 2012), h. 90. lihat pula Fachruddin, Ensiklopedia Al-Qur'an, (Jakarta : PT. Rineka Cipta, 1992), h. 608-609. dan Abdul Azis Dahlan, et al., Ensiklopedi Hukum Islam, (Jakarta: PT Ichtiar Baru Van Hoeve, Cet. Ke-1, 1996), h. 944. 


\section{AL-MARSHAD: JURNAL ASTRONOMI ISLAM DAN ILMU-ILMU BERKAITAN \\ ISSN 2442-5729 (print) || ISSN 2598-2559 (online) \\ http://jurnal.umsu.ac.id/index.php/almarshad \\ DOI: 10.30596/jam.v\% vi\%i.5092 || Vol. 6, No. 2 Desember 2020}

kegiatan perhitungan dan pengukuran. ${ }^{15}$ Dalam perhitungan ataupun pengukuran, sangat erat kaitannya dengan akurasi, dalam KBBI akurasi berarti kecermatan, ketepatan, dan ketelitian. ${ }^{16}$ Arah kiblat yang dimaksud secara astronomis yaitu arah menuju titik koordinat $21^{\circ} 25^{\prime}$ LU dan $39^{\circ} 50^{\prime}$ BT dalam hal ini di ukur dari letak kawasan tertentu di Indonesia yang berada pada interval koordinat $9^{\circ} \mathrm{LU}$ $11^{\circ} \mathrm{LS}$ dan $95^{\circ}-141^{\circ} \mathrm{BT}$. Pengukuran arah kiblat ini merupakan kedudukan yang dinyatakan dengan sudut terhadap suatu titik $^{17}$ dalam hal ini titik tersebut adalah bangunan Ka'bah di Mekah. Sudut arah kiblat kemudian dinyatakan dalam berbagai tinjauan, dapat dinyatakan dengan tinjauan sudut terdekat dalam arah mata angin tertentu dan dapat pula dinyatakan dengan tinjauan yang dimulai dari titik utara berputar searah jarum jam sebagaimana tinjauan azimuth pada umumnya. Berdasarkan tinjauan tinjauan tersebut maka koordinat arah kiblat akan bernilai antara $20^{\circ} \mathrm{UB}$ sampai $26^{\circ}$ UB atau $290^{\circ}$ UTSB sampai $296^{\circ}$ UTSB apabila pengukuran arah kiblat di

\footnotetext{
${ }^{15}$ Khafid, Telaah Pedoman Buku Hisab Arah Kiblat, (Cibinong : RHI, 2013), h. 28.

${ }^{16}$ Petter Salim dan Yenny Salim, Kamus Bahasa Indonesia Kontemporer, (cet 111, Jakarta: Modern English Press, 2002), h. 36.

${ }^{17}$ Liek Wilarjo, Dad dan Murniah, Kamus Fisika, (cet 2, Jakarta: Balai Pustaka, 2003), h. 71.
}

lakukan di Indonesia.

Arah kiblat juga dapat dilakukan pada momen tertentu yang disebut dengan istilah rashdul qiblah. Rashdul qiblah merupakan suatu peristiwa saat matahari berada segaris lurus di atas Ka'bah sehingga bayangan benda mengarah ke Ka'bah. ${ }^{18}$ Momen rashdul qiblah terjadi tanggal 27 mei tahun kabisat jam 11:57:16 LMT atau 09:17:56 GMT atau tanggal 28 mei tahun basithah jam 11:57:16 LMT atau 09:17:56 GMT. Selain itu juga terjadi tanggal 15 juli tahun kabisat jam 11:57:16 LMT atau 09:17:56 GMT dan 16 juli tahun basithah jam 12:06:03 LMT atau 09:26:43 GMT. ${ }^{19}$

\section{Dasar Hukum Salat Menghadap ke Arah} Kiblat

Awal yang mendasari perintah arah kiblat berasal dari kisah Rasulullah saw setelah beliau hijrah dari Mekah ke Madinah. Rasulullah Muhammad saw seringkali menghadapkan wajahnya ke langit sambil merindukan Ka'bah hingga suatu hari malaikat Jibril mendatangi beliau atas perintah Allah

${ }^{18}$ Rashdul qiblah disebabkan oleh perubahan posisi kedudukan matahari yang berada pada deklinasi tertentu dimana nilai deklinasi tersebut sama dengan lintang Ka'bah.

${ }^{19}$ Muhyiddin Khazin, Ilmu Falak Dalam Teori dan Praktik (Yogyakarta: Buana Pustaka, 2008), h.72. lihat pula Arwin Juli Rakhmadi Butar-Butar, Pengantar Ilmu Falak Teori, Praktek, dan Fikih, (Cet. I; Depok: PT Raja Grafindo Persada, 2018), h. 63. 


\section{AL-MARSHAD: JURNAL ASTRONOMI ISLAM DAN ILMU-ILMU BERKAITAN \\ ISSN 2442-5729 (print) || ISSN 2598-2559 (online) \\ http://jurnal.umsu.ac.id/index.php/almarshad \\ DOI: 10.30596/jam.v\% vi\%i.5092 || Vol. 6, No. 2 Desember 2020}

swt. $^{20}$ Pada bulan Sya'ban II H. beliau mendatangi kabilah bani Salamah yang berada di pinggiran utara Madinah bersama sejumlah sahabat. Ketika memasuki waktu dzuhur, Rasulullah Muhammad saw melaksanakan salat terlebih dahulu sebelum menyantap hidangan yang telah disiapkan oleh Ummi Basyar. Ketika melaksanakan salat inilah Rasulullah saw. yang sebelumnya menghadap ke Baitul Maqdis kemudian mendapatkan perintah Allah swt. untuk menghadap ke Masjidil Haram. $^{21}$ Mengetahui hal ini Abbas bin Bisyir juga memberikan kabar bahwa nabi Muhammad saw telah menerima wahyu untuk menghadap Ka'bah kepada penduduk Quba yaitu Bani Amr ibn Auf yang ketika itu melaksanakan salat subuh maka mereka kemudian memutar arah ketika sedang melaksanakan salat tersebut. ${ }^{22}$

Ayat Al-Qur'an yang dijadikan dasar hukum menghadap ke kiblat: sebagai berikut:

${ }^{20}$ Muhammad Husain Haikal, Sejarah Hidup Muhammad, (Jakarta : PT. Dunia pustaka Jaya. 1982), h. 238

${ }^{21}$ Moenawar Chalil, Kelengkapan Tarikh Nabi Muhammad saw, ( Jakarta :Gema Insan Press. 2001), h 272

${ }^{22}$ Muhammad Hasbi Asshiddieqy, Mutiara Hadits 3 Shalat, (Semarang : PT. Pustaka Rizki Putra, 2003), h. 23-25.
QS Al-Baqarah/2:144

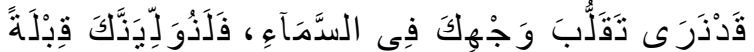

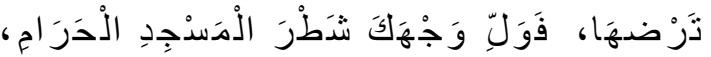

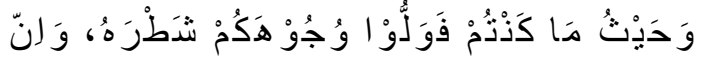

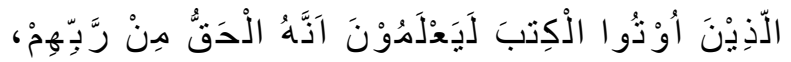

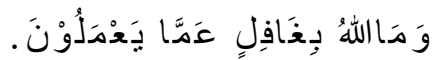

Terjemahnya:

"Kami melihat wajahmu (Muhammad) sering menengadah ke langit, maka kami palingkan engkau ke kiblat yang engkau senangi. Maka hadapkanlah wajahmu ke arah Masjidil Haram. Dan dimana saja engkau berada, hadapkanlah wajahmu ke arah itu. Dan sesungguhnya orang - orang yang diberi kitab (Taurat dan Injil) tahu, bahwa (pemindahan kiblat) itu adalah kebenaran dari Tuhan mereka. Dan Allah tidak lengah terhadap apa yang mereka kerjakan." 23

QS Al-Baqarah/2:149

$$
\begin{aligned}
& \text { وَمِنْ حَيْتُ خَرَجْتَ فَوَلَّ وَجْهَكَكَ شَطْرَ الَْسَسْجِدِ }
\end{aligned}
$$

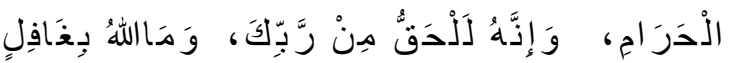

$$
\begin{aligned}
& \text { عَمََّا تَحْْْمَلُوْْنَ. }
\end{aligned}
$$

Terjemahnya:

"Dan dari mana pun engkau (Muhammad) keluar, hadapkanlah wajahmu ke arah Masjidil Haram. Dan sesungguhnya itu benar-benar ketentuan dari Tuhanmu. Allah tidak lengah terhadap apa yang kamu kerjakan".

QS Al-Baqarah/2:150

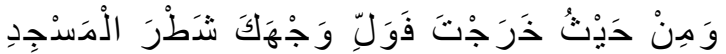

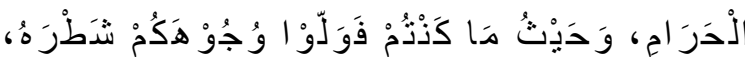

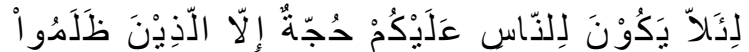

\footnotetext{
${ }^{23}$ Tim Penyusun, Al Quran Terjemah
}

Indonesia, (Jakarta: Kementrian Agama RI, 2016), h.22. 


\section{AL-MARSHAD: JURNAL ASTRONOMI ISLAM DAN ILMU-ILMU BERKAITAN \\ ISSN 2442-5729 (print) || ISSN 2598-2559 (online) \\ http://jurnal.umsu.ac.id/index.php/almarshad \\ DOI: 10.30596/jam.v\%vi\%i.5092 || Vol. 6, No. 2 Desember 2020}

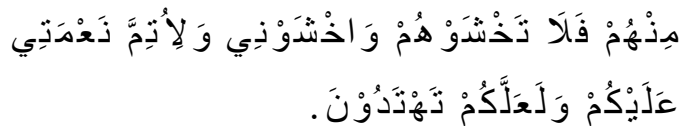

Terjemahnya:

"Dan dari mana pun engkau (Muhammad) keluar maka hadapkanlah wajahmu ke arah Masjidil Haram. Dan dimana saja kamu berada maka hadapkanlah wajahmu ke arah itu agar tidak ada alasan bagi manusia (untuk menentangmu) kecuali orang-orang yang zalim diantara mereka. Janganlah kamu takut kepada mereka, tetapi takutlah kepada-Ku agar aku sempurnakan nikmat-Ku kepadamu dan agar kamu mendapat petunjuk." 24

Dalam menyikapi permasalahan terkait arah kiblat ini Majelis Ulama Indonesia (MUI) mengeluarkan fatwa No.3 tahun 2010 yang menganggap bahwa letak Indonesia berada di sebelah timur Ka'bah sehingga arah barat adalah arah kiblat. ${ }^{25}$ Hal ini untuk menenangkan masyarakat yang mulai khawatir terhadap arah kiblat masjid - masjid di Indonesia. Namun setelah fatwa ini di keluarkan ternyata mendapat berbagai macam tanggapan dari para praktisi Ilmu Falak. Fatwa No. 3 tahun 2010 dianggap tidak tepat karena letak Indonesia yang tidak persis di sebelah timur Ka'bah. Majelis

\footnotetext{
${ }^{24}$ Tim Penyusun, Al Quran Terjemah Indonesia, h.23.

${ }^{25}$ Komisi Fatwa MUI, Fatwa Tentang Arah Kiblat, Fatwa No.3 Tahun 2010, (Jakarta: Majelis Ulama Indonesia, 2010), h.8.
}

Ulama Indonesia (MUI) kemudian mengeluarkan lagi fatwa No. 5 tahun 2010 sebagai penjelas fatwa No. 3 tahun $2010^{26}$ dengan mempertimbangkan masukan para praktisi Ilmu Falak terhadap keakuratan aspek pengukuran.

\section{Hasil dan Pembahasan}

\section{Penentuan Arah Kiblat Saadoeddin Djambek}

Saadoeddin Djambek dalam metode penentuan arah kiblatnya menggunakan lintang dan bujur Ka'bah $21^{\circ} 25^{\prime} \mathrm{LU}$ dan $39^{\circ}$ 50 ' BT. Hal ini berdasarkan penelitian yang ia lakukan saat menjabat ketua Badan Hisab dan Rukyat di Jakarta.

Untuk mengetahui metode penentuan arah kiblat Saadoeddin Djambek diperlukan beberapa langkah yang harus diketahui terlebih dahulu yaitu :

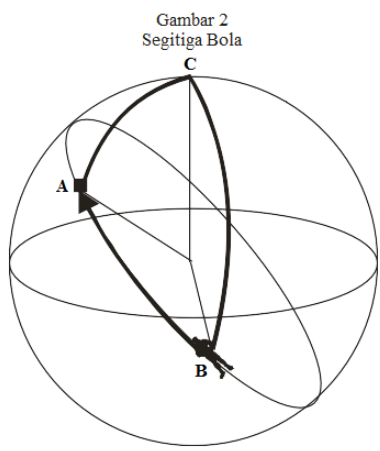

1. Titik A, terletak di Ka'bah,

2. Titik B, terletak di lokasi yang akan

\footnotetext{
${ }^{26}$ Komisi Fatwa MUI, Fatwa Tentang Arah Kiblat, Fatwa No.5 Tahun 2010, h.7.
} 


\section{AL-MARSHAD: JURNAL ASTRONOMI ISLAM DAN ILMU-ILMU BERKAITAN \\ ISSN 2442-5729 (print) || ISSN 2598-2559 (online) \\ http://jurnal.umsu.ac.id/index.php/almarshad \\ DOI: 10.30596/jam.v\% vi\%i.5092 || Vol. 6, No. 2 Desember 2020}

dihitung arah kiblatnya, ${ }^{27}$ dan

3. Titik C, terletak di titik kutub Utara.

Asumsi pada konsep tersebut memanfaatkan tiga titik yang kemudian ketiga titik $\mathrm{A}, \mathrm{B}$ dan $\mathrm{C}$ dihubungkan dengan garis lengkung yang melalui garis lingkaran besar bola dihubungkan sehingga membentuk segitiga bola. Garis lengkung yang berada di depan sudut A adalah garis a, garis lengkung yang berada di depan sudut $B$ adalah garis $b$ dan garis lengkung yang berada di depan sudut $\mathrm{C}$ adalah garis c. Sehingga hubungan setiap garis lengkung dan sudut dapat dituliskan dalam rumus sinus sebagai berikut :

$$
\frac{\sin \mathrm{a}}{\sin \mathrm{A}}=\frac{\sin \mathrm{b}}{\sin \mathrm{B}}=\frac{\sin \mathrm{C}}{\sin \mathrm{C}}
$$

Berdasarkan hubungan pada segitiga bola tersebut Saadoeddin Djambek kemudian membuat rumus :

\section{Rumus I}

Rumus I (satu) Saadoeddin Djambek merupakan pengembangan dari rumus trigonometri bola. Pada rumus ini arah kiblat dihitung berdasarkan penarikan nilai cotan sudut, hal ini dilakukan karena pada awalnya rumus ini dioperasikan dengan menggunakan peta grafik kiblat yang

${ }^{27}$ Saadoeddin Djambek, Arah Qiblat, (Jakarta : Tintamas, 1958), h. 14. sebelumnya telah dibuat berdasarkan nilai cotan sudut.

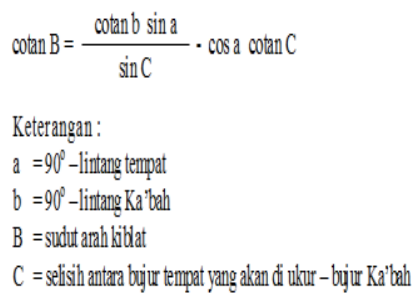

2. Rumus II

Rumus II (dua) Saadoeddin Djambek dioperasikan dengan memanfaatkan data hasil pada tabel logaritma. Pada rumus ini sudut bantu $\mathrm{p}$ dihitung terlebih dahulu untuk memudahkan pengoperasian rumus.

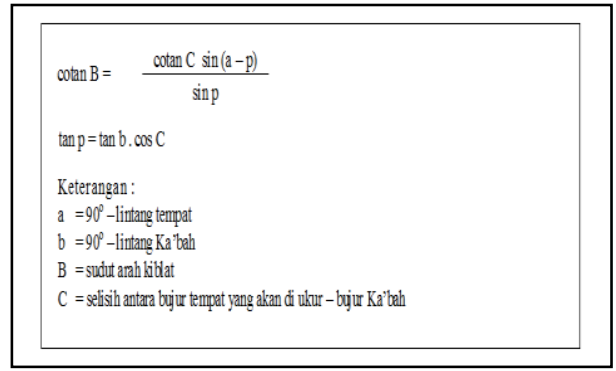

\section{Rumus III}

Pada rumus III (tiga) Saadoeddin Djambek menggunakan nilai tan guna memudahkan dalam pengoprasian menggunakan alat hitung.

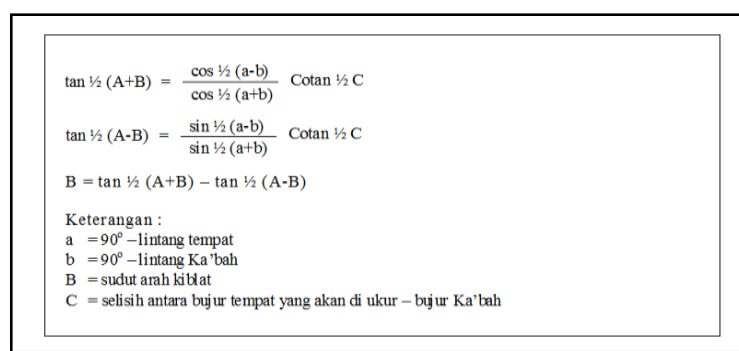

Metode penentuan arah kiblat Saadoeddin Djambek ini berangkat dari 


\section{AL-MARSHAD: JURNAL ASTRONOMI ISLAM DAN ILMU-ILMU BERKAITAN \\ ISSN 2442-5729 (print) || ISSN 2598-2559 (online) \\ http://jurnal.umsu.ac.id/index.php/almarshad \\ DOI: 10.30596/jam.v\% vi\%i.5092 || Vol. 6, No. 2 Desember 2020}

teori spherical

trigonometry

(trigonometri bola) dan rumus analogi Napier yang keduanya merupakan perhitungan arah kiblat berlandaskan pada ilmu Geometri. ${ }^{28}$ Saadoeddin Djambek memanfaatkan rumus analogi Napier dalam rumus tiganya untuk menghitung salah satu sudut diantara dua titik dalam segitiga bola sehingga sudut antara dua tempat dipermukaan bumi ini bisa diketahui secara ideal dan matematis. ${ }^{29}$

\section{Penentuan Arah Kiblat spherical trigonometry}

Teori arah kiblat yang paling banyak diterapkan secara spherical trigonometry adalah teori trigonometri bola (spherical trigonometry) yang dicetuskan oleh $\mathrm{Abu}$ Raihan Al-Biruni dengan konsepnya yang mengasumsikan bentuk bumi seperti bentuk bola bulat sempurna. Al-Biruni melakukan pengukuran geodesi dengan beberapa kalkulasi astronomi kemudian ia menentukan lintang dan bujur, ia adalah orang pertama yang menolak teori

\footnotetext{
${ }^{28}$ Ibn Kholdun, Muqaddimah Ibnu Khaldun, (Iskandariah : Daarul Baidhu, tt.),h. 71.

${ }^{29}$ Agus Solikin, Perhitungan Arah Salat, (Semarang : Pascasarjana IAIN Semarang, 2013), h. 3.
}

geocentris Ptolomeus. ${ }^{30}$

Telah dijelaskan sebelumnya bahwa hubungan antara tiga titik yang membentuk segitiga bola dapat dituliskan dengan rumus sinus. Selain rumus sinus, hubungan antara ketiga titik ini juga dapat dituliskan ke dalam rumus cosinus berikut ini :

$$
\begin{aligned}
& \operatorname{Cos} a=\cos b \cos c+\sin b \sin c \cos A \\
& \operatorname{Cos} b=\cos a \cos c+\sin a \sin c \cos B \\
& \operatorname{Cos} c=\cos a \cos b+\sin a \sin b \cos C
\end{aligned}
$$

Adapun rumus arah kiblat spherical trigonometry yang diadaptasi dari rumus trigonometri bola adalah sebagai berikut :

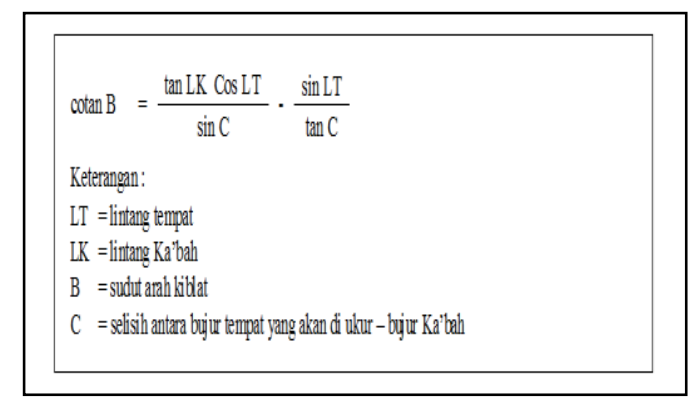

Komparasi Metode Saadoeddin Djambek dan Metode spherical trigonometry

Setiap rumus diharapkan memiliki tahapan yang praktis dan hasil yang akurat. Pada hakikatnya rumus dibuat untuk memudahkan perhitungan yang rumit. Rumus dibuat dengan mempertimbangkan detail pengoperasian dan keakurasiannya.

Perbandingan penentuan arah Kiblat Saadoeddin Djambek dan penentuan arah

\footnotetext{
${ }^{30}$ Ahmad Baiquni, Al-Quran Ilmu Pengetahuan dan Teknologi, (Cet. 4, Yogyakarta: Dana Bhakti Prima Yasa, 1996), h. 9.
} 


\section{AL-MARSHAD: JURNAL ASTRONOMI ISLAM DAN ILMU-ILMU BERKAITAN \\ ISSN 2442-5729 (print) || ISSN 2598-2559 (online) \\ http://jurnal.umsu.ac.id/index.php/almarshad \\ DOI: 10.30596/jam.v\% vi\%i.5092 || Vol. 6, No. 2 Desember 2020}

kiblat spherical trigonometry dengan mengoperasikan rumus arah kiblat dapat dilihat pada uraian berikut ini:

Rumus I Saadoeddin Djambek:

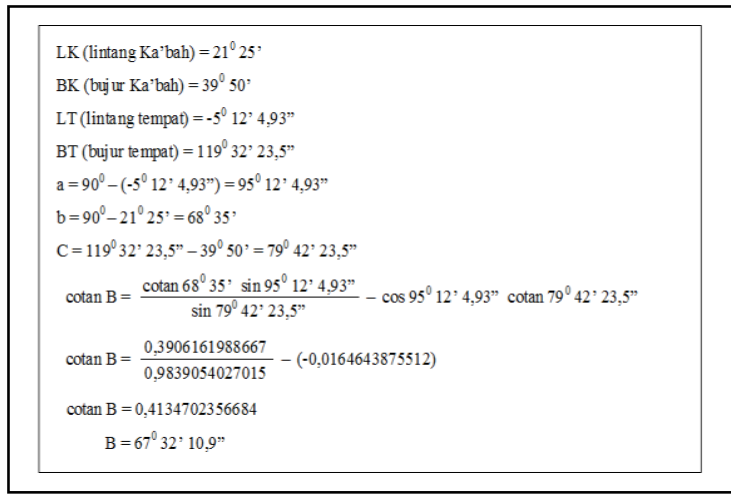

Pada pengoperasian rumus I (satu) dapat diketahui bahwa diperlukan data awal koordinat lokasi dan koordinat arah kiblat. Selanjutnya menentukan nilai variabel $a, b$, dan C. Setelah mendapatkan nilai variabel-variabel tersebut kemudian nilai dari variabel-variabel tersebut di subtitusi masuk ke dalam rumus. Variabelvariabel yang disubtitusi masuk ke dalam rumus kemudian melalui proses operasi hitung yang cukup sederhana.

Rumus II Saadoeddin Djambek:

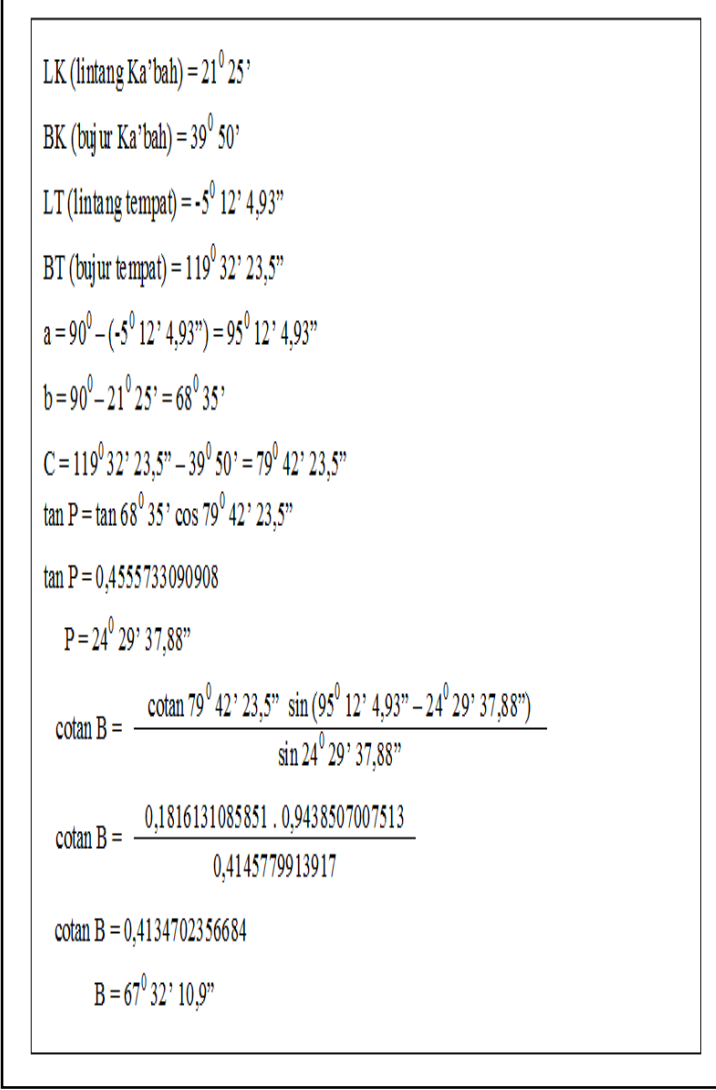

LK (lintang Ka'bah) $=21^{0} 25^{\prime}$

BK (bujur Ka'bah) $=39^{0} 50^{\prime}$

LT $($ lintang tempat $)=-5^{0} 12^{\prime} 4,93^{\prime \prime}$

BT $($ bujur tempat $)=119^{0} 32^{\prime} 23,5^{\prime \prime}$

$\mathrm{a}=90^{0}-\left(-5^{0} 12^{\prime} 4,93^{\prime \prime}\right)=95^{0} 12^{\prime} 4,93^{\prime \prime}$

Pada pengoperasian rumus II (dua) diketahui bahwa sama seperti pada rumus I (satu) yakni diperlukan data awal koordinat lokasi dan koordinat arah kiblat. Selanjutnya menentukan nilai variabel a, b, dan C. Setelah diketahui nilai variabel-variabel $\mathrm{a}, \mathrm{b}$ dan $\mathrm{C}$ selanjutnya menentukan nilai sudut bantu $\mathrm{p}$. setelah mendapatkan nilai sudut bantu $\mathrm{p}$ dan nilai-nilai dari variabel $\mathrm{a}, \mathrm{b}$ dan $\mathrm{C}$ kemudian nilai dari sudut bantu $\mathrm{p}$ dan variabel-variabel 


\section{AL-MARSHAD: JURNAL ASTRONOMI ISLAM DAN ILMU-ILMU BERKAITAN \\ ISSN 2442-5729 (print) || ISSN 2598-2559 (online) \\ http://jurnal.umsu.ac.id/index.php/almarshad \\ DOI: 10.30596/jam.v\%vi\%i.5092 || Vol. 6, No. 2 Desember 2020}

tersebut di subtitusi masuk ke dalam rumus. Pada awalnya rumus ini menggunakan tabel logaritma untuk memudahkan proses hitung namun pada masa sekarang proses perhitungan lebih mudah dengan adanya kalkulator scientific. Adapun proses operasi hitung pada rumus II (dua) juga terbilang cukup sederhana.

Rumus III Saadoeddin Djambek:

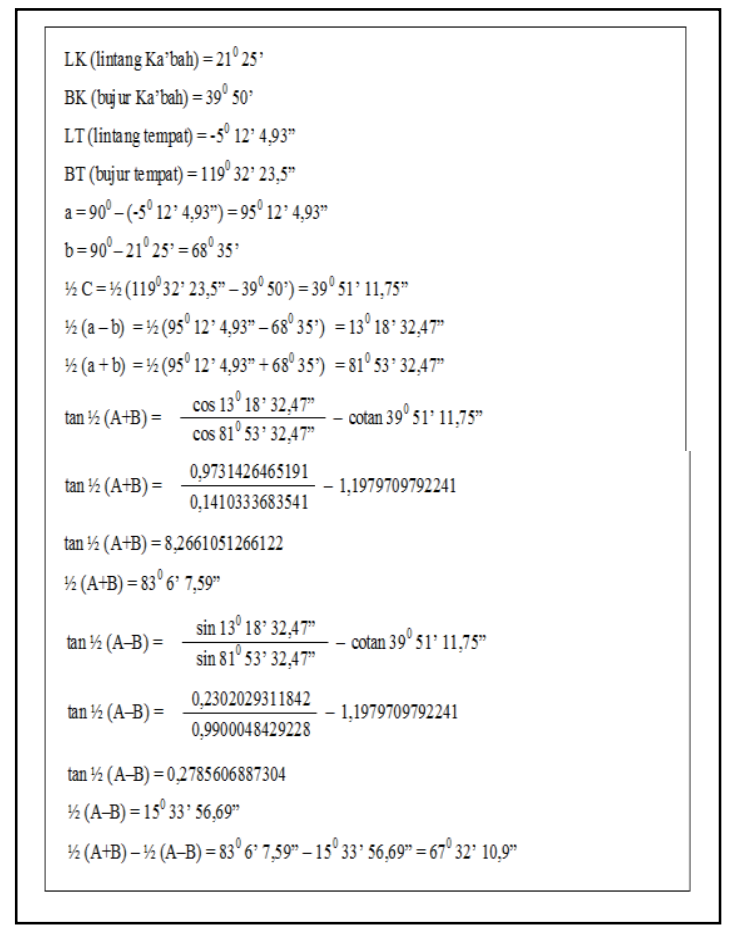

Pada pengoperasian rumus III (tiga) diketahui bahwa sama seperti pada rumus I dan rumus II yakni diperlukan data awal koordinat lokasi dan koordinat arah kiblat. Selanjutnya menentukan nilai variabel $a, b$, dan $1 / 2$ C. Disini ada sedikit perbedaan dari rumus I dan rumus II karena variabel yang digunakan adalah nilai $1 / 2 \mathrm{C}$ atau nilai setengah sudut C. Setelah diketahui nilai variabel-variabel $\mathrm{a}, \mathrm{b}$ dan $1 / 2 \mathrm{C}$ selanjutnya menentukan nilai $1 / 2(a-b)$ dan nilai $1 / 2(a+b)$ atau nilai setengah dari hasil penjumlahan dua sisi. setelah mendapatkan nilai-nilai tersebut kemudian di subtitusi masuk ke dalam rumus. Rumus III Saadoeddin Djambek ini dibuat berdasarkan analogi Napier. Pada rumus III ini proses hitung terbilang cukup rumit.

Rumus spherical trigonometry:

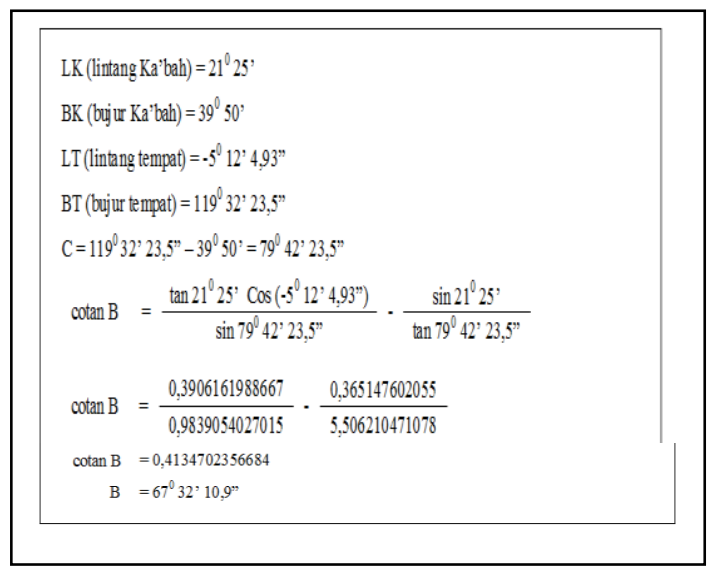

Pada pengoperasian rumus spherical trigonometry juga diperlukan data awal koordinat lokasi dan koordinat arah kiblat. Namun berbeda dengan rumus Saadoeddin Djambek, pada rumus spherical trigonometry hanya dibutuhkan nilai variabel $\mathrm{C}$ saja. Selanjutnya data awal lintang tempat dan lintang Ka'bah yang di operasikan ke dalam rumus sebagai variabel bersama dengan nilai variabel C. Operasi hitung pada rumus spherical trigonometry ini lebih sederhana apabila dibandingkan dengan ketiga rumus Saadoeddin Djambek. Adapun hasil 


\section{AL-MARSHAD: JURNAL ASTRONOMI ISLAM DAN ILMU-ILMU BERKAITAN \\ ISSN 2442-5729 (print) || ISSN 2598-2559 (online) \\ http://jurnal.umsu.ac.id/index.php/almarshad \\ DOI: 10.30596/jam.v\% vi\%i.5092 || Vol. 6, No. 2 Desember 2020}

perhitungan dari ketiga rumus Saadoeddin Djambek dan rumus spherical trigonometry menghasilkan nilai sudut arah kiblat yang sama yakni $67^{0} \quad 32$ ' 10,9 ”. Nilai ini merupakan nilai sudut arah kiblat dihitung dari arah utara ke barat (UB). Dengan demikian berarti ketiga rumus Saadoeddin Djambek dan rumus spherical trigonometry memiliki nilai keakuratan yang sama dalam menentukan arah kiblat.

\section{Kesimpulan}

Pada dasarnya metode penentuan arah kiblat Saadoeddin Djambek dan spherical trigonometry yang banyak digunakan merupakan rumus turunan dari rumus trigonometri bola karya Al-Biruni sehingga secara garis besar keduanya memiliki banyak kesamaan. Namun telah mengalami perbedaan besar dalam operasi hitungnya. Rumus spherical trigonometry juga tidak memerlukan banyak variabel tambahan sehingga tahapan operasi hitungnya lebih sederhana. Adapun keakuratan rumus-rumus Saadoeddin Djambek dan rumus spherical trigonometry terbilang sama sehingga keberadaan rumus spherical trigonometry ini memperkuat keberadaan rumus-rumus sebelumnya. Selain itu data lintang dan bujur Ka'bah versi Saadoeddin Djambek yang merupakan hasil penelitian beliau juga masih banyak digunakan. Ini merupakan salah satu bukti besarnya peran Saadoeddin Djambek terhadap perkembangan Ilmu Falak di Indonesia.

Peneliti memiliki harapan agar tulisan ini berguna dalam pembelajaran Ilmu Falak, dalam memahami rumus, pelatihan pengukuran arah kiblat ataupun sebagai bahan penelitian-penelitian selanjutnya oleh para penggiat Ilmu Falak.

\section{Daftar Pustaka}

Muhammad Hasbi Asshiddieqy. 2003. Mutiara Hadits 3 Shalat. Semarang : PT. Pustaka Rizki Putra.

Susiknan Azhari. 2008. Ensiklopedi Hisab Rukyat. Yogyakarta : Pustaka Pelajar.

Susiknan Azhari. 2002. Pembaharuan Pemikiran Hisab di Indonesia. Yogyakarta : Pustaka Pelajar.

Ahmad Baiquni. 1996. Al-Quran Ilmu Pengetahuan dan Teknologi. Yogyakarta: Dana Bhakti Prima Yasa.

Arwin Juli Rakhmadi Butar-Butar. 2018. Pengantar Ilmu Falak Teori, Praktek, dan Fikih. Depok: PT Raja Grafindo Persada.

Moenawar Chalil. 2001. Kelengkapan Tarikh Nabi Muhammad saw. Jakarta: Gema Insan Press.

Abdul Azis Dahlan. 1996. Ensiklopedi Hukum Islam. Jakarta: PT Ichtiar Baru Van Hoeve.

Departemen Agama RI. 1994. Pedoman Penentuan Arah Kiblat. Jakarta: Dirjen Binbaga Islam.

Saadoeddin. Djambek. 1958. Arah Qiblat. Jakarta : Tintamas. 


\section{AL-MARSHAD: JURNAL ASTRONOMI ISLAM DAN ILMU-ILMU BERKAITAN \\ ISSN 2442-5729 (print) || ISSN 2598-2559 (online) \\ http://jurnal.umsu.ac.id/index.php/almarshad \\ DOI: 10.30596/jam.v\%vi\%i.5092 || Vol. 6, No. 2 Desember 2020}

Fachruddin. 1992. Ensiklopedia AlQur'an. Jakarta : PT. Rineka Cipta.

Muhammad Husain Haikal. 1982.Sejarah Hidup Muhammad. Jakarta : PT. Dunia Pustaka Jaya.

Slamet Hambali. 2011.Ilmu Falak I Tentang Penentuan Awal Waktu Shalat dan Penentuan Arah Kiblat Di Seluruh Dunia. Semarang: PPS IAIN Walisongo.

Ibn Kholdun. Muqaddimah Ibnu Khaldun. Iskandariah : Daarul Baidhu, tt.

Khafid. 2013.Telaah Pedoman Buku Hisab Arah Kiblat. Cibinong : RHI.

Muhyiddin Khazin. 2008. Ilmu Falak Dalam Teori dan Praktik. Yogyakarta: Buana Pustaka.

Komisi Fatwa MUI. 2010. Fatwa Tentang Arah Kiblat, Fatwa No.3 Tahun 2010. Jakarta: Majelis Ulama Indonesia.

Komisi Fatwa MUI. 2010.Fatwa Tentang Arah Kiblat, Fatwa No.5 Tahun 2010. Jakarta: Majelis Ulama Indonesia.

Kusdiono. 2002. Ilmu Ukur Segitiga Bola. Bandung : Jurusan Teknik Geodesi.

Majlis Tarjih Dan Tajdid Pimpinan Pusat Muhammadiyah. . 2009. Pedoman Hisab Muhammadiyah. Yogyakarta : Majlis Tarjih Dan Tajdid Pimpinan Pusat Muhammadiyah.

Ahmad Warson Munawir. 1997. AlMunawir kamus Arab-Indonesia. Surabaya: Pustaka Progressif.

Rizal Mustansyir. 2001. Filsafat Ilmu. Yogyakarta: UGM Press.

Harun Nasution. 1992. Ensiklopedi Hukum Islam. Jakarta: Djambatan.

Nurmal Nur. 1997. Ilmu Falak: Teknologi Hisab Rukyat Untuk
Menentukan Arah Kiblat, Awal Waktu Shalat dan Awal Bulan Qamariah. Padang: IAIN Imam Bonjol Padang.

Ali Parman. 2012. Ilmu Falak. Makassar: Alauddin University Press.

Petter Salim dan Yenny Salim. 2002. Kamus Bahasa Indonesia Kontemporer. Jakarta: Modern English Press.

Nourouzzaman Shiddiqi. 1997. Fiqh Indonesia Penggagas dan Gagasannya. Yogyakarta, Pustaka Pelajar.

Agus Solikin. 2013. Perhitungan Arah Salat. Semarang : Pascasarjana IAIN Semarang.

Dendy Sugono. 2008. Kamus Besar Bahasa Indonesia Pusat Bahasa. Jakarta : PT. Gramedia Pustaka Media.

Tim Penyusun. 2016. Al Quran Terjemah Indonesia. Jakarta: Kementrian Agama RI.

Liek Wilarjo. dkk. , 2003. Kamus Fisika. Jakarta: Balai Pustaka. 